\title{
Exercise rescues mitochondrial coupling in aged skeletal muscle: a comparison of different modalities in preventing sarcopenia
}

Colin Harper ${ }^{1}$, Venkatesh Gopalan ${ }^{2}$ and Jorming Goh $3,4,5^{*}$ (I)

\begin{abstract}
Skeletal muscle aging is associated with a decline in motor function and loss of muscle mass- a condition known as sarcopenia. The underlying mechanisms that drive this pathology are associated with a failure in energy generation in skeletal muscle, either from age-related decline in mitochondrial function, or from disuse. To an extent, lifelong exercise is efficacious in preserving the energetic properties of skeletal muscle and thus may delay the onset of sarcopenia. This review discusses the cellular and molecular changes in skeletal muscle mitochondria during the aging process and how different exercise modalities work to reverse these changes. A key factor that will be described is the efficiency of mitochondrial coupling-ATP production relative to $\mathrm{O}_{2}$ uptake in myocytes and how that efficiency is a main driver for age-associated decline in skeletal muscle function. With that, we postulate the most effective exercise modality and protocol for reversing the molecular hallmarks of skeletal muscle aging and staving off sarcopenia. Two other concepts pertinent to mitochondrial efficiency in exercise-trained skeletal muscle will be integrated in this review, including- mitophagy, the removal of dysfunctional mitochondrial via autophagy, as well as the implications of muscle fiber type changes with sarcopenia on mitochondrial function.
\end{abstract}

Keywords: Skeletal muscle, Mitochondria, Aging, Exercise

\section{Introduction}

Harman's free radical theory of aging proposed that aging is associated with the accumulation of oxidative damage to proteins, lipids and DNA in living tissues [1]. Such damages could impair the normal functioning of the adenosine triphosphate (ATP) producing organelles-the mitochondria, resulting in deficient energy production. Studies in older humans have documented an age-related decrease in aerobic capacity, suggesting that mitochondrial dysfunction or loss in skeletal muscle could be the underlying mechanism. Indeed, a number of hallmark changes occur in skeletal muscle mitochondria with aging

*Correspondence: jorming@nus.edu.sg

${ }^{3}$ Healthy Longevity Translational Research Program, Yong Loo Lin School of Medicine, National University of Singapore (NUS), Singapore, Singapore Full list of author information is available at the end of the article including increases in mitochondrial DNA (mtDNA) deletions [2], reductions in enzyme activity and mtDNA content, and increases in oxidative stress [3]. Some studies, however, implicate increased sedentarism which usually accompanies human aging as a greater culprit for such decline of skeletal muscle function than the aging itself.

The first part of this review will briefly describe the mechanisms involved in oxidative phosphorylation in the mitochondria of skeletal muscle. Subsequently, there will be a discussion on the hallmark mitochondrial changes that occur in skeletal muscle with aging as well as an examination of the evidence for and against aging, or physical inactivity, being the primary cause of abnormal energetics in aged skeletal muscle. Regardless of whether sedentary living or aging per se is at the root of declining energy metabolism, physical demands of daily living present a challenge to older individuals. 
Hence, the final part of this review will investigate the mechanisms by which different exercise forms restore mitochondrial energetics and compare these different exercise forms in their effectiveness to prevent mitochondrial aging and intercept sarcopenic development in older adults.

\section{Skeletal muscle mitochondria-powerhouses to drive locomotion}

Energy is needed for movement. In human locomotion, this energy is derived from ATP, a large percentage of which is generated in the mitochondria, via the process of oxidative phosphorylation. Two membranes envelop the mitochondrion-the inner membrane and the outer membrane, where the former allows the passage of $\mathrm{H}^{+}$, which forms the crux of the mechanism for energy transduction during oxidative phosphorylation [4]. Small molecules and ions pass through transmembrane channels embedded in the outer membrane.

Cristae are the invaginations of the inner membrane, and the matrix, the compartment lying within the inner membrane, is the site in which the reducing equivalents nicotinamide adenine dinucleotide (NADH) and flavin adenine dinucleotide $\left(\mathrm{FADH}_{2}\right)$ transfer electrons to the electron transport chain (ETC) [5]. Preceding events at the ETC is the oxidation of substrates through the Krebs cycle, which generates the bulk of the reducing equivalents described above. The ETC is a system of four enzyme complexes [5] that perform sequential reduction-oxidation reactions (4), systematically transporting the electrons across each of the complexes to ultimately reduce $\mathrm{O}_{2}$ and generate $\mathrm{H}_{2} \mathrm{O}$, while pumping protons out of the matrix along the way.

As electrons are moved from complex I to complex IV, protons are actively translocated by complexes I, III and IV to the intermembrane space of the mitochondrion. This movement of ions generates an electrochemical gradient between the intermembrane space and the matrix [5], with the matrix becoming more negatively charged and the intermembrane space becoming more positively charged [4]. Consequently, as protons flow down the electrochemical gradient and through the ATP synthase (complex V) into the matrix, adenosine diphosphate (ADP) is phosphorylated to ATP [4].

The capacity for, and efficiency of, ATP synthesis are two concepts that will be relevant for the discussion on mitochondrial function in this manuscript. How much ATP is synthesized depends on the flux through the ETC as well as the rate of oxygen uptake [5]. These factors are, in turn, determined by the energy demand of the cell, which, when high, ATP breakdown is augmented. This then increases [ADP] and $\left[\mathrm{P}_{\mathrm{i}}\right]$, which stimulate ATP regeneration [4]. Therefore, energy demand drives ATP synthesis. An important concept in understanding mitochondrial oxidative phosphorylation is the distinction between State 3 and State 4 respiration. These two terms define the metabolic state of mitochondria; state 3 respiration takes place when there are both ADP and other respiratory substrates available, whereas State 4 respiration occurs in the absence of ADP [4]. State 3 respiration, also called "active respiration", is characterized by maximal ATP synthesis and oxygen uptake, during which the rate of respiration is 5-8 times faster than that of State 4 [4]. It has been described that $60-70 \%$ of mammalian aerobic respiration occurs in State 4, with the rest occurring in State 3.

Whether aging itself or sedentary living typically associated with old age is the phenomenon primarily responsible for declining ATP synthesis, is a subject of continued debate. The coupling of ATP synthesis per molecule of oxygen consumed is known as the $\mathrm{P} / \mathrm{O}$ ratio [6]. In essence, the $\mathrm{P} / \mathrm{O}$ ratio defines the coupling efficiency of mitochondrial oxidative phosphorylation and is a useful working tool to quantitatively compare rates of ATP production relative to oxygen consumption. Energy production and efficiency relevant to the discussion of aging skeletal muscle will be the basis of discussion in the next section.

\section{Does age-associated oxidative stress cause mitochondrial impairment in skeletal muscle?}

Reactive oxygen species (ROS) are generated during normal respiration, with approximately $0.1-2 \%$ of $\mathrm{O}_{2}$ reduced to form superoxide [5,7], the main source of oxidative stress in the cell [8], which is generated primarily at complexes I and III of the ETC [9]. Most of the superoxide produced in the mitochondria is released to the matrix, with a smaller proportion channeled to the intermembrane space [4]. Other ROS generated in the mitochondria include $\mathrm{H}_{2} \mathrm{O}_{2}$ and $\mathrm{NO}$ which, together with superoxide, augment oxidation of lipids, proteins and DNA of mitochondria [5], leading to damage of these constituents. Higher rates of production of ROS such as $\mathrm{H}_{2} \mathrm{O}_{2}$ occur during State 4 respiration than during State 3 respiration [4]. It was also reported that State 4 respiration was higher in skeletal muscle of 24-month old rats, compared with 4-month old rats, while the ATP produced per $\mathrm{O}_{2}$ consumed ( $\mathrm{P} / \mathrm{O}$ ratio) was lower in aged rats relative to young rats [10]. These results have implications that give credence to the oxidative damage theory of aging. That is, mitochondria of older organisms are less efficient at generating ATP for a given amount of oxygen, possibly as a consequence of increased ROS damage to mitochondria, which is also associated with increased $\mathrm{H}^{+}$ leak and increased uncoupling. This mechanism could explain the age-related decline in muscle function. 
The studies above summarize the mitochondrial theory of aging, an extension of the free radical theory of aging, which attributes free radical damage on mitochondrial components as the cause of mitochondrial dysfunction [4]. Because the respiratory chain is a major producer of ROS, the membrane's proximity to the mitochondrial genome, along with mtDNA's lack of protective histones and less robust repair mechanisms compared to the nuclear genome [9], makes mtDNA especially susceptible to ROS-induced mutations. In a nutshell, the mitochondrial theory of aging states that accumulation of mtDNA mutations results in aberrant or decreased expression of ETC protein complexes, which in turn leads to progressive uncoupling of the ETC and thereby increased generation of radical species, giving rise to a vicious cycle of further oxidative damage, mtDNA mutations, and respiratory uncoupling. Supporting the idea that free radical-induced damage is correlated with aging, a study by Mansouri and colleagues [8] demonstrated that mitochondria isolated from the hind-limb skeletal muscle of old (28-29 month) mice produced $50-80 \%$ higher $\mathrm{H}_{2} \mathrm{O}_{2}$, depending on substrate added, than young (6-8 month) mice. The older mice also had higher oxidative damage to mtDNA, as evidenced by higher levels of 8-oxo-2deoxyguanosine (oxo8dG). Congruently, age-related functional deficits were reflected by a $30 \%$ reduction in ATP production in the old mice, compared with the young mice.

However, while high levels of ROS damage macromolecular structures, low levels of ROS are thought to confer greater stress resistance and even lifespan extension through an adaptive defense response known as "mitohormesis" [11]. Specifically, low level ROS presence is thought to induce mitochondrial stress response mechanisms that enable better tolerance of subsequent stressors as well as induce mtDNA repair mechanisms. Therefore, there seems to be an adaptively beneficial range of ROS presence beyond which the effects grow increasingly deleterious on mtDNA. With aging and sedentarism, however, the upper threshold of this range is far surpassed. Thus, exercise that increases coupling efficiency, and thereby mitigates electron leakage and excessive ROS generation, could restore the range to a baseline, favorable levels as seen in healthy adults.

More importantly, duration (acute vs chronic) seems to be a major determinant of whether ROS production is adaptive or destructive. Acute, exercise-induced ROS generation is associated with the benefits of increased mitochondrial biogenesis and muscle hypertrophy, while chronic basal elevations of ROS generally act pathologically [12]. For example, it has recently been shown that aerobic exercise induces acute bouts of oxidative stress which trigger mitohormesis via activation of the redoxsensitive transcription factor Nrf2, an endogenous antioxidant gene, resulting in protection against sarcopenia [13].

\section{Mitochondrial DNA deletion-mutations in aging muscle}

The aforementioned findings by Mansouri et al. are consistent with other animal and human studies that reported the following age-related changes in skeletal muscle mitochondria: increased mtDNA deletions-mutations [14-18] and damage [14], decreased mitochondrial DNA abundance $[14,19]$ and decreased mitochondrial protein synthesis [20]. In fact, the prevalence of mtDNA deletions in human skeletal muscle increases so predictably and proportionately with age that it has been considered for use in age estimation [21].

Increased mtDNA deletion in biopsies obtained from the vastus lateralis of older human subjects was detected with polymerase chain reaction (PCR) [16] and found to be correlated with a cytochrome-c oxidase negative/ succinate dehydrogenase-hyperreactive $\left(\mathrm{COX}^{-} / \mathrm{SDH}^{++}\right)$ muscle phenotype. This peculiar phenotypic expression is typical of impaired oxidative phosphorylation, where the morphological change in the muscle manifests as a "ragged red" appearance, owing to the staining pattern used with the modified Gomori technique [17]. Mechanistically, this indicates SDH activity accompanied by decreased cytochrome-c oxidase (COX) activity, and thus is a manifestation of aberrant ETC activity. The researchers of this study examined the abundance of mtDNA deletion-mutation along the length of the muscle fibers and demonstrated that the distribution of the deletion-mutations clustered at regions where there was expression of the $\mathrm{COX}^{-} / \mathrm{SDH}^{++}$phenotype. Their results supported the hypothesis that mitochondrial abnormalities are concomitant with aging. The evidence, however, is not convincing because muscle samples were obtained autopsies of a small sample of subjects $(N=12)$ that varied in age, causes of death and body weight. This makes the older subjects in the sample heterogeneous and unlikely to be representative of people in their age group.

Two previous studies by the same group [15, 17] assessed mitochondrial function of different muscle groups isolated from rats. In those studies, age correlated with the expression of the $\mathrm{COX}^{-} / \mathrm{SDH}^{++}$phenotype. They also reported that the cross-sectional area of the fibers decreased within the $\mathrm{COX}^{-} / \mathrm{SDH}^{++}$region and that there was fiber splitting in those regions. Interestingly, the length of the abnormal region was associated with fiber atrophy: the mean length of the $\mathrm{COX}^{-} / \mathrm{SDH}^{++}$ region was $239 \pm 17$ microns for 5-month-old rats, $266 \pm 33$ microns for 18-month-old rats, and $267 \pm 14$ microns for 38-month-old rats [15]. Hence, systematic 
atrophy in aged skeletal muscle fibers of rats appeared to be associated with abnormal ETC phenotypic expression.

In an effort to elucidate a more specific role of mtDNA deletion-mutations in muscle aging, Herbst and colleagues [18] quantified the amount of mutant and wild-type mitochondrial genomes along the lengths of muscle fibers dissected from aged (36-month) rats. They reported that within each $\mathrm{COX}^{-} / \mathrm{SDH}^{++}$region, the abundance of mutated mitochondrial genomes was greater than $90 \%$. Wild-type genomes, on the other hand, were localized at areas that were further from regions with the aberrant expression. Therefore, it is possible that the genetic machinery is mutated to such a detrimental extent that the normal phenotypic expression of the muscle fibers is impaired. To further confirm the causality between mtDNA deletions and sarcopenia, Herbst et al. [22] pharmacologically induced the same type of mtDNA deletion mutation that is observed to accumulate in aged skeletal muscle in aged rat muscle. Both muscle fiber number and muscle mass decreased in proportion with the amount of deletion induced, affirming the fact that ETC-altering deletion-mutations of mtDNA contribute to skeletal muscle deterioration with aging.

Subsequently, Herbst et al. [23] speculated that maladaptive mitochondrial biogenesis may act as the driving force behind the amplification and spread of mtDNA deletion-mutations, finding that induction of mitochondrial biogenesis via treatment of middle-aged rats with $\beta$-Guanidinopropionic acid resulted in a 3.7-fold increase in the number of ETC-aberrant fibers. More recently, the mechanism for propagation of ETC-aberrant fibers has been further elucidated by analysis of isolated human skeletal muscle tissue [24]. It was found that ETC-abnormal fibers containing mtDNA mutations were localized with elevations of mitochondrial mass and mtDNA copy number. It is speculated, then, that the energetic insufficiencies caused by mtDNA deletion-mutations and the accompanying ETC defects induce mitochondrial biogenesis in a compensatory cellular effort to restore adequate energy production, and thereby engender a vicious cycle of propagating these mutations [23]. Specifically, it is believed, mitochondrial biogenesis first generates focal accumulation of clonal deletion-mutated mtDNA, and that mutant mitochondria subsequently propagate transversely along the muscle fiber following mitochondrial networks, hence the anisotropic mosaic pattern of COX-/ $\mathrm{SHD}^{++}$fibers [24].

In any case, mtDNA mutations are relevant to the conversation of mitochondrial energetic decline as their rates have been correlated with bioenergetic deficiency, particularly of complex IV, and muscle atrophy [25]. Complex IV, being the terminal electron acceptor of the ETC, plays a crucial role here in that increasing its activity may mitigate electron leakage and thereby reduce ROS production [26]. Given that ET [14, 27, 28] and RT [2] have been shown to upregulate complex IV activity, dampening mtROS generation by reducing electron leakage may be one of the protective mechanisms of exercise on mitochondria.

\section{The impact of aging on mitochondrial gene expression and protein synthesis}

Skeletal muscle mitochondrial gene expression and protein synthesis are also impacted by age. Muscle fibers of old rats (27-month) contain lower copy numbers of mtDNA than those of young rats (6-month) [19]. This was also accompanied by reduced COX transcripts in highly oxidative tissues (soleus) but not in less oxidative tissues (gastrocnemius). Likewise, in a human study, the investigators found an inverse relationship between age and the abundance of skeletal muscle mtDNA and mRNA that encoded for COX3 and COX4 [29]. Moreover, the older subjects showed higher oxidative damage (8-oxo-dG) and diminished mitochondrial ATP production rate with age.

Given an age-associated decrease in mtDNA expression, the next level of enquiry would be to examine the translational levels of mitochondrial proteins in the aged. Similar to findings in gene expression, isotopic mass spectrometry analysis of fractional rate of protein synthesis in skeletal muscle demonstrated higher (40\%) mitochondrial protein synthesis rate in young humans ( $24 \pm 1$ years), compared with middle aged ( $54 \pm 1$ years) and older humans (73 \pm 2 years) [20]. In this study, COX and citrate synthase enzyme activities were also inversely related to age. Thus, the implication is that genetic alterations are being carried over to the protein level and eventually manifest in changes to enzymatic activities.

The role of the mitochondria is to supply ATP to the different cells within the organism. In addition to the accrual of oxidative damage to structural components of mitochondria, functional deficits are possibly incurred, particularly in energy production. In a review of the literature by Russ and Kent-Braun [30], a common finding amongst studies was that oxidative capacity in skeletal muscle of the older adults was lower than young individuals. These studies comprised cross-sectional analyses of human subjects that differed in age and physical activity levels, and both in vitro and in vivo methods were used to measure oxidative capacity in their skeletal muscles.

\section{Insights on mitochondrial function from in vitro experiments}

The in vitro experiments involved isolation of muscle biopsies from human subjects, followed by quantification of activity levels of oxidative enzymes such as citrate synthase, SDH and COX using fluorometric techniques. Key findings from these studies indicated that there 
is a decline in oxidative capacity in aged skeletal muscle as a function of age, as shown by reduced enzymatic activities. Unfortunately, the results were confounded by physical activity, which were surveyed differently in the studies. For example, some studies measured physical activity using self-reported questionnaires, while others measured whole body maximal oxygen consumption $\left(\mathrm{VO}_{2 \max }\right)$ during treadmill testing [30]. The problem with this approach is that the first method does not allow the investigators to accurately assess habitual physical activity due to recall bias of the participants. Secondly, the value of $\mathrm{VO}_{2 \max }$ as a tool to assess physical activity patterns is undermined by the contribution of genetic potential-that is, some sedentary individuals are genetically endowed with high aerobic potential. Thus, it is not a true measure of physical activity habits.

These inconsistencies have prompted scholars in the field to argue that reduced oxidative capacity in skeletal muscle is probably not a correlate of age, but rather a result of declining habitual physical activity [30]. Supporting this viewpoint is the finding that no differences in citrate synthase or SDH activities existed between endurance-trained young and old individuals [30]. Therefore, it seems, reduced enzymatic activities in mitochondria of old individuals may be partly, if not mostly, attributable to decreased physical activity associated with age, rather than by the aging process itself.

An additional weakness with the in vitro assays lies in the techniques used to quantify the activities of the mitochondrial enzymes, since they give information on the function of mitochondria under an artificial environment: enzymatic analyses involve measuring the activities of the enzymes in solution and not in their natural environment within the mitochondria. In situ analysis of mitochondria is a solution to this problem as it allows oxidative enzymes to be studied within their normal environments, that is, inside the mitochondria. Secondly, this technique measures the integrity of the respiratory chain as well as ATP synthesis, which are more robust measures of oxidative capacity than assaying only a few enzymes of the tricarboxylic cycle. Using this technique, Rasmussen et al. [31, 32] found that out of 13 different enzyme activities assayed, age accounted for just two of the differences ( $\beta$-oxidation and $\alpha$-glycerophosphate dehydrogenase) in the activities, whereas the others (e.g., respiratory chain, tricarboxylic acid cycle, COX, citrate synthase, ATP synthesis) were not significantly influenced by age. In addition, State 4 respiration was not higher and $\mathrm{P} / \mathrm{O}$ ratios were not lower for the older adults compared with the young subjects. Congruently, a more recent study found that while $\mathrm{P} / \mathrm{O}$ ratios of older sedentary adults are markedly depressed, $\mathrm{P} / \mathrm{O}$ ratios are similar between young active adults and old active adults [33], further supporting the notion that coupling efficiency is much more dependent on physical activity level than on age. Thus, the argument that reduced oxidative capacity is a consequence of aging continues to be challenged, by both results from in vitro and in vivo experiments.

\section{Insights on mitochondrial function from in vivo experiments}

The in vivo experiments described in Russ and KentBraun's review paper [30] utilize magnetic resonance spectroscopy (MRS). In general, these experiments are based on following the changes in metabolites such as ATP, $\mathrm{PCr}, \mathrm{Pi}$ and changes in $\mathrm{pH}$ to portray real-time muscle respiration. Using MRS [34-40] to quantify muscle metabolism confers some advantages over the methodology of in vitro experiments. These advantages include: (i) obtaining a larger tissue mass than tissue biopsies that are used for in vitro assays, (ii) offering a more functional depiction of oxidative capacity in the whole muscle under physiological conditions, as opposed to isolated conditions that are reliant on non-physiological concentrations of mitochondrial substrates. Nevertheless, the in vivo experiments did not offer much resolution to the conflict over aging and mitochondrial dysfunction. Some studies showed decreased oxidative capacity in skeletal muscle from older adults, whereas others found no significant differences between young and old skeletal muscle. These studies are discussed in the following sections.

\section{Reduced mitochondrial coupling and sarcopenia in aging}

In one study [41], $\mathrm{VO}_{2}$ max was negatively related to age, with the older adults' ( $69 \pm 6$ years old) oxygen consumption $\sim 45 \%$ of the adult ( $39 \pm 8$ years old) value. Cross-sectional areas of the quadriceps muscles of older subjects were also 33\% lower than the young adults. When corrected for smaller muscle volume in the older adults, oxidative capacity was $36 \%$ of that in the adult muscle. Another study [42], however, found no differences in oxidative capacity between the old ( $75 \pm 5$ years old) and young ( $33 \pm 5$ years old). An explanation for this discrepancy could be traced to the muscles that were studied. In the first study, the quadriceps were studied, while the tibialis anterior was analyzed for the latter. It is likely that muscle-specific differences exist in aging skeletal muscle, possibly due to the different proportions of type I and II fibers within the muscles. The tibialis anterior and the vastus lateralis are comprised of 25 and 60\% type II fibers, respectively [43].

Conley's group [43] reported no significant difference between older and younger adults for both mitochondrial coupling and ATP concentration in the tibialis anterior. On the other hand, differences in both energetic 
properties were apparent for the vastus lateralis, with muscle from older adults exhibiting decreased $\mathrm{P} / \mathrm{O}$ and [ATP]. This disparity in mitochondrial function between type I/"slow-twitch" (aerobic/oxidative phosphorylative) and type II /"fast-twitch" (anaerobic/glycolytic) fibers supports the contributing role of ROS in mitochondrial dysfunction; type II fibers generate 2-3 times higher $\mathrm{H}_{2} \mathrm{O}_{2}$ than type I fibers [44]. Increased ROS production is responsible for the increased apoptotic process in type II muscle fibers, leading to preferential loss of such fibers with aging [43]. These results suggest that mitochondrial uncoupling is associated with aging in skeletal muscle and could be an underlying mechanism for inefficient energy production, lowered [ATP] within myocytes, and increased apoptosis of type II fibers that manifests as sarcopenia.

Physical activity may be a confounding factor in investigating mitochondrial dysfunction and sarcopenia, although the results from Conley et al. [43] show that the tibialis anterior, which like the vastus lateralis, is also recruited during locomotion, has comparable bioenergetic functions in older versus young adult subjects. Contrarily, differences were found for the vastus lateralis. As the subjects in this study were recreationally active, as assessed by physical activity questionnaires, the implication is that intrinsic changes within the skeletal muscle in the older population could lead to the lower energy properties, even when the older persons are physically active.

Nevertheless, the characteristic macroscopic manifestation of skeletal muscle degeneration with aging appears as follows: loss of both type I and type II fibers with preferential loss of type II fibers, as well as increase in aberrant $\mathrm{COX}^{-} / \mathrm{SDH}^{++}$fibers. The physiologic mechanisms that underly and collectively engender the aforementioned phenotypic changes are both extrinsic, resulting from global and systemic changes with aging, and intrinsic, resulting from changes that occur within the myocytes and their organelles. Among the extrinsic causes are progressive denervation, altered endocrine and autocrine regulation, satellite stem cells declines, and altered protein metabolism $[45,46]$. The intrinsic mechanisms, on the other hand, include the aforementioned: reduced protein synthesis, DNA damage and mtDNA deletionmutations, as well as impaired mitochondrial dynamics and decreased autophagic and mitophagic degradation, which will be discussed in the following section. These intrinsic changes, particularly the energetic ones, are less understood and are the focus of this review.

One of the causes of fiber size and quantity decline is myofiber mitochondrial dysregulation which fosters generation of oxygen radicals which in turn damage the nuclear and mitochondrial genomes, ultimately resulting in decreased protein expression and, consequently, atrophy or even apoptosis of the myofibers. Congruent with this explanatory model, it has been demonstrated that mitochondrial free radical generation $\left(\mathrm{H}_{2} \mathrm{O}_{2}\right.$ produced $/ \mathrm{O}_{2}$ consumed) is two- to threefold higher in type IIB fibers than in type I fibers in situ [47]. This intrinsic difference in myofiber properties most likely accounts for the accelerated decline of type II fibers, particularly type IIB, with aging.

\section{Compromised mitochondrial quality control and impaired mitophagy with aging}

A defining element of mitochondrial dynamics and a critical one to upholding mitochondrial integrity is constant turnover via cycles of generation, dynamics and clearance of the mitochondrial reticulum achieved by the processes of biogenesis, fusion/fission, and mitophagy respectively. Of these, biogenesis is the most well studied. The process of mitochondrial biogenesis, the expansion of the existing mitochondrial network through both growth and division, is constantly ongoing in myofibers but declines with aging [48]. However, aged skeletal muscle possesses a reduced capacity to induce biogenesis in response to biogenesis-inducing stimuli such as muscular contraction [49]. Peroxisome proliferator-activated receptor gamma coactivator $1 \alpha(\mathrm{PGC}-1 \alpha)$ is the master regulator of mitochondrial biogenesis, along with other purposes such as glucose and fatty acid metabolism [50]. PGC- $1 \alpha$ serves as a coactivator for a number of nuclear genes encoding mitochondrial proteins, one of which is transcription factor A of the mitochondria (Tfam), a critical regulator of mitochondrial biogenesis and coordinator of nuclear and mitochondrial genomes [51]. PGC-1 $\alpha$, along with Tfam, has been found to decrease with age in rodents, but aerobic exercise has been well demonstrated to attenuate these declines and increase PGC-1 $\alpha$, Tfam, and nuclear respiratory factor 1 (NRF1), the three key inducers of mitochondrial biogenesis. For example, just 12 weeks of aerobic exercise in older rats attenuated age-related declines of PGC- $1 \alpha$ and Tfam, restoring expression to levels even higher than that of young untrained rats [52]. Likewise, aerobic training in both older and younger adults has been demonstrated to increase PGC- $1 \alpha$ expression by $55 \%$ [53]. Although human results have been inconsistent, age-related reductions in PGC-1 $\alpha$ may be partly responsible for the decline in mitochondrial volume in aged skeletal muscle. Thus, upregulating PGC- $1 \alpha$ and TFAM, and thereby augmenting mitochondrial biogenesis, may be one avenue by which exercise preserves muscle mitochondrial quality and myofiber quality.

Mitochondrial quality is tightly regulated via fine balance between fusion and fission, two opposing processes which are constantly reshaping mitochondrial 
architecture to optimize for functional demands. Fusion refers to the spatial expansion of the mitochondrial network primarily via proteins mitofusin 1 (Mfn1) and mitofusin 2 (Mfn2). In contrast, mitochrondrial fission is the process of dividing the network into fragmented, globular mitochondria. The balance between these two processes is critical to upkeeping effective mitochondria and skeletal muscle function, but with aging is often compromised. Some studies indicate that aging confers dysregulation in the direction of disproportionately elevated fission [54], consistent with the fragmented mitochondrial structures often observed in aged rodent skeletal muscle [55]. Particularly, Mfn2 levels appear to decline progressively with age as demonstrated in rodent studies, a deficiency that drives mitochondrial dysfunction and impairs mitophagy [56]. Conversely, aerobic training in older adults increases the ratio of fusion to fission proteins, favoring a more fused, tubular mitochondrial network [57]. Congruently, another key operator in fusion, mitochondrial protein, optic atrophy 1 (OPA1), in addition to Mfn1, has been shown to decline with age in sedentary, but not active, adults [58]. Age-related decline of skeletal muscle Opa1 is likewise apparent in mice, but, in one study, only 1 week of aerobic exercise proved sufficient to reactivate its expression in aged mice [58]. Therefore, aerobic exercise appears to be a putative intervention to rebalance the scale of mitochondrial dynamics by upregulating mitochondrial fusion.

One possible fate of mitochondrial fragments postfission is lysosomal degradation via a process known as mitophagy, mitochondria-targeted autophagy. Mitophagy is critical in clearing aberrant or diseased mitochondria. However, with age, mitophagy declines [59], particularly in skeletal muscle [60]. Compromised mitophagy predictably results in mitochondrial damage accumulation, augmented oxidative stress, and increased apoptosis, which together culminate in both myopathy and muscular atrophy [61]. Thus, impaired mitophagy is likely a key player in the pathophysiological progression of sarcopenia and is a potential target for intervention.

Although understanding of its role is only recently emerging, mitophagy increasingly appears to be a critical mechanism of exercise-induced remodeling, but human data on the matter remain imperfect $[62,63]$, as studies have relied upon indirect indicators of mitophagy: changes in gene expression or protein concentration of mitophagic regulators. While the complexities of both mitophagy and the innovative methods of its detection are beyond the scope of the review, what is of pertinence is that mitophagy may be one of the key avenues by which exercise rescues myofiber mitochondria. In one rodent study, for example, aerobic exercise resulted in enhance mitophagy flux, as well as enhanced targeting of mitochondria for degradation, increasing mitochondrial turnover; moreover, this outcome appeared to be PGC- $1 \alpha$ dependent, as results were not replicated in PGC-1 $\alpha^{-/-}$mice [64]. Remarkably, another study in mice demonstrated that a single bout of treadmill running stimulates post-exercise autophagy 3 times higher than that of basal expression levels in skeletal muscle, in an AMPK/Ulk1-dependent manner [65]. Like aerobic training, resistance training also appears to be a potent inducer of skeletal muscle autophagy. For example, in one study, the skeletal muscle of 18-20 month old rats that underwent 9 weeks of resistance training exhibited enhanced autophagy and reduced myocytic apoptosis, presumably via inhibition of the Akt/mTOR pathway and activation of the FOXO3a pathway [66].

\section{Exercise training in older adults-can it restore mitochondrial energetics? \\ Endurance training}

Although the exact nature of mitochondrial dysfunction in aging has yet to be determined, there is consensus that regular exercise can help maintain muscle mass and aerobic fitness [67]. Endurance training (ET) is well known to improve oxidative capacity [68] and induce mitochondrial biogenesis [69] in skeletal muscle. ET acts multifariously to improve muscle quality and energetic coupling in older individuals and thereby holds great potential in ameliorating sarcopenia. ET has been well documented to prevent age-associated loss of oxidative capacity [70]. For example, in one study, endurance-trained older men (51-62 years old) possessed SDH activities in type I and IIa muscle fibers at levels comparable to younger (2130 years old) endurance-trained individuals. This elevation in enzyme activity persisted even though the older trained individuals, like their untrained, age-matched counterparts, had smaller cross-sectional areas of type II fibers than the younger men. This study encompassed a cross-sectional design, with subjects recruited based on their habitual physical activity. Hence, it is not clear as to the temporal sequence of whether regular exercise maintains muscle oxidative capacity or vice versa. More recently, another study assayed vastus lateralis biopsies of young and old endurance-trained men vs. age-matched sedentary men. Oxidative phosphorylation proteins were universally elevated in the active groups, and COX activity significantly higher in active old individuals than in their sedentary counterparts, supporting the findings of the aforementioned study [71].

However, numerous interventional trials have since elucidated the temporal sequence, confirming the fact that ET improves muscle oxidative capacity. While the aforementioned findings lack causative rigor, ET, when performed in clinical interventions, consistently 
improves muscle health metrics and energetics, especially in aged individuals. For instance, increases in mtDNA and activity of the ETC, particularly of complex I and complex II, were observed after 12 weeks of ET in healthy older ( $67.3 \pm 0.6$ years old) persons that were previously sedentary [28]. The observed improvements in mitochondrial function were thought to be a result of observed increases in mitochondrial biogenesis. Congruently, Short and colleagues [14] reported that 16 weeks of ET in men and women aged between 21 and 87 years conferred not only improvements in peak oxygen uptake ( $\mathrm{VO}_{2}$ peak), but also increases in skeletal muscle mitochondrial enzyme activities and mRNA expressions (citrate synthase and COX) and genes involved in mitochondrial biogenesis (PGC-1 $\alpha$, NRF-1, TFAM). These changes occurred regardless of age, indicating that biological adaptations to exercise training were preserved in aged skeletal muscle. A caveat in this study lies in the small sample size for each age-group, with approximately 6 subjects per decade. This could potentially limit the generalizability of the results. Furthermore, another limitation of the study is that protein synthesis was not measured for the genes that mediate mitochondrial biogenesis; thus, whether exercise-induced changes in gene expression was translated to the protein level was not confirmed.

Perhaps the most comprehensive study on the potential of ET to rescue age-related mitochondrial energy decline is the work of Broskey et al. [27]. First, they found that active individuals exhibited not only an average mitochondrial volume density $48.9 \%$ greater than that of age-matched sedentary individuals, but also significantly higher activity of electron transport complexes I, IV, and V. Second, they found that when sedentary individuals engaged in moderate-intensity endurance exercise for 16 weeks (diet remaining unchanged), not only did mitochondrial volume density increase by $50.7 \%$ concomitant with increases in PGC- $1 \alpha$ and TFAM gene expression, but electron transport complexes III, IV, and V were also dramatically upregulated. These findings together confirm that physical activity level is a greater determinant of mitochondrial energetic capacity than aging itself, and thus the observed mitochondrial decline in aged individuals is likely more so an outcome of decreased activity levels, rather than of aging itself. A caveat of the implications of the study lies in the fact that while oxidative capacity was indeed increased by aerobic exercise, the actual ratio of $\mathrm{ATP}_{\max }$ to mitochondrial volume density remained unchanged. That is, oxidative capacity improved not due to functional changes in oxidative coupling efficiency, but instead due to increased mitochondrial biogenesis and thus increased mitochondrial volume.
While the previously cited trials indicated that oxidative capacity improves secondary to augmented mitochondrial biogenesis, other studies have reported improvements in phosphorylation capacity and $\mathrm{ATP}_{\text {max }}$ independent of or disproportionate to changes in mitochondrial volume [72, 73], suggesting intrinsic changes in mitochondrial function. Conley et al. [72] found that 6 months of ET of aged individuals $(69.5 \pm 1.2$ years old) resulted in a significant increase in $\mathrm{ATP}_{\max }$ as well as a $31 \%$ increase in oxidative capacity, but was unaccompanied by any increase in mitochondrial volume, indicating improved coupling efficiency [72]. That is, the ratio of phosphorylation capacity to the ratio of mitochondrial volume $\left(\mathrm{ATP}_{\max } / \mathrm{V}_{\mathrm{V}}\right)$ increased, hence intrinsic energy coupling increased. An important difference between this and aforementioned ET studies may account for these disparate findings. That is, the training modalities and intensities in this study differ from other ET protocols: while most of the aforementioned studies involve biking, running, rowing, or walking at a moderate intensity ( $75 \%$ of maximum heart rate), in this study, subjects used a "one-legged press" StairMaster machine as well as a kayak-simulating machine at a heart rate of $80-85 \%$ [73]. Both of these, in addition to being conditioning exercises, are weight-loaded and therefore possess some element of resistance training, as reflected in the greater weight lifted post-intervention and the relatively small increase in $\mathrm{VO}_{2} \max$ (only 5.4\%) compared to that of the other ET studies, despite the greater programme length. Thus, the question is raised: do the mitochondrial benefits conferred by exercise differ based on training modality-increased mitochondrial volume for ET and enhanced coupling efficiency for resistance training? This will be investigated in the following section.

Regarding ET intensity, it seems that higher intensity training confers more rapid, more significant improvements in mitochondrial respiratory capacity. In a study by Granata et al. [74], 4 weeks of sprint-interval training (4-10 $\times 30$ s all-out bouts at $\sim 200 \%$ of peak power output), but not HIIT, or sublactate threshold continuous training, increased maximal mitochondrial respiration as well as PGC- $1 \alpha$ and p53 protein content, as well as mitochondrial respiration, but not mitochondrial content or ETC subunit content. Congruently, another study found that a single bout of high intensity $\left(80 \%\right.$ of $\mathrm{VO}_{2}$ $\max )$ cycling engendered a 10.2-fold increase in PGC-1 $\alpha$ mRNA while isocaloric low intensity $\left(40 \%\right.$ of $\mathrm{VO}_{2}$ max) engendered an only 3.8-fold increase PGC- $1 \alpha$ mRNA [75]. A worthwhile consideration for this manifestation is differential fiber recruitment and differential fiber response properties. Specifically, training at $80 \%$ of $\mathrm{VO}_{2}$ max recruits primarily type II fibers while training at $40 \%$ of $\mathrm{VO}_{2}$ max recruits primarily type I fibers. Work by 
Russell et al. [76] has indicated that type II fibers possess a greater capacity to upregulate PGC- $1 \alpha$ transcription in response to training stimulus. Specifically, after 6 weeks of interval training at $70-80 \%$ of $\mathrm{VO}_{2}$ max, an intensity similar to the high intensity group in the aforementioned trial, PGC- $1 \alpha$ protein content increased 2.8-fold in type IIa fibers and 1.5-fold in type I and type IIx fibers. Thus, the greater induction of PGC- $1 \alpha$ expression via high intensity ET than moderate intensity ET is likely attributable to its greater recruitment of type II fibers. Interestingly, a recent study found that continuous endurance training ( $~ 65 \%$ of $\left.\mathrm{VO}_{2} \max \right)$ and HIIT $\left(\sim 170 \%\right.$ of $\mathrm{VO}_{2}$ $\max )$ for 6 weeks confer very similar changes in intramuscular signaling and even fiber-type recruitment, with almost no differences in outcome with the exception being that HIIT training conferred greater improvements in anaerobic and glycolytic capacity [77].

In addition to its energetic impacts, ET also modulates the level of oxidative damage in skeletal muscle. Two animal studies $[78,79]$ demonstrated that treadmill running for 8 or 10 weeks attenuated the content of oxo8dG and increased the activities of Oxoguanine DNA glycosylase (OGG1) and Uracil DNA glycosylase (UDG), respectively, in skeletal muscle of aged (30-month and 21-month-old) rats. It is inferred that at least in animal studies, exercise exerts a positive effect on aged skeletal muscle by reducing oxidative damage through upregulation of DNA repair mechanisms. In addition to upregulating DNA repair mechanisms and bolstering antioxidant defense mechanisms [80], ET may also reduce oxygen damage by mitigating electron leakage, by improving electron flux, and thereby reducing ROS generation.

Another potential benefit of endurance training, as mentioned in earlier sections, is its ability to reverse age-associated declines in autophagy in skeletal muscle. After 8 weeks of treadmill running $5 \times$ per week, key autophagic regulators autophagy-related gene 7 and beclin-1 expression levels were restored in 12 month old mice [81]. Such findings are consistent with other studies and similar upregulations in autophagy can be seen even with single bouts of training. For example, in one study [82], following a single bout of swimming, several autophagic proteins, Atg5, Atg7, p62, and LC3-II, were upregulated and Ulk1 phosphorylation, a key state in autophagic regulation, was increased in the gastrocnemius of 24 month old mice. Moreover, the effect of aerobic training on skeletal muscle autophagy may be dependent on exercise intensity. In one study, moderate intensity treadmill running $(20 \mathrm{~m} / \mathrm{min})$ predictably increased autophagy gene expression. Conversely, however, high intensity $(30 \mathrm{~m} / \mathrm{min})$ treadmill running, which is above the mouse lactate threshold of $20 \mathrm{~m} /$ min, resulted in diminished autophagy gene expression
(83). Low intensity running, however, engendered no significant changes in autophagy gene expression. Thus, aerobic exercise seems to induce autophagy in a bimodal response and may be optimized with moderate intensity ET.

\section{Resistance training}

Muscle strength declines with aging to a greater degree and at a greater rate than does muscle mass, indicating a decrease in muscle "quality" with age [84]. Skeletal muscle loss with aging is primarily attributed to a loss of type II muscle fibers [85], which is closely related to muscle "quality" and peak force which diminishes with sarcopenia. Resistance training (RT) directly increases type II muscle fiber size and number [85] and therefore is a worthy candidate for intervention against sarcopenia. While the evidence for the mitochondrial benefits of ET are robust, the effects of RT on mitochondrial coupling has been much less studied. All resistance training is not created equal-the repetition range is highly determinate of which energy systems are utilized and therefore of how mitochondria are recruited and modulated. Thus, as most RT can be classified as anaerobic activity, with the exception of high repetition training, RT, in theory, has less to do with mitochondria than does ET. So while the aforementioned benefits of RT in increasing muscle mass and strength, maintaining function and mobility, and improving metabolic health have been widely demonstrated [86], RT's mitochondrial effects are less established. Nevertheless, recent evidence indicates that RT may also improve skeletal muscle mitochondrial function and restore muscle energetics in older individuals, with early evidence in older adults demonstrating that chronic RT intervention not only phenotypically ameliorates muscle weakness, but also markedly reverses the transcriptional signatures of age-associated mitochondrial impairment, restoring the mitochondrial transcriptome to that of a younger adult [87].

Skeletal muscle hypertrophy is typically accompanied by new myonuclei within muscle fibers, which are primarily derived from myosatellite cells, or muscle stem cells. However, recent work indicates a differential relationship between myonuclear accrual and muscular hypertrophy between type I and type II fibers, suggesting differential mechanisms of hypertrophy between the two types. Following 12 weeks weeks of resistant training in older ( $71 \pm 4.4$ years old) adults, type II fiber hypertrophy was predictably much greater than type I fiber hypertrophy ( 23 vs $8 \%$ ), despite myonuclear content only increased in type I fibers [88]. The authors, Moro et al. [88], thus speculate that type II myonuclei are able to upregulate transcriptional activity to a degree that supports RT-induced hypertrophy in the absence of satellite 
cell differentiation or myonuclear accrual. This reflects one of a number of ways in which hypertrophic processes differ by fiber type.

Porter et al. [89] found that 12-week full-body RT at a range of 3-4 sets of 8-10 repetitions increased electron transfer capacity by $65 \%$, and significantly enhanced maximal coupling respiration along with intrinsic mitochondrial function, without augmenting mitochondrial biogenesis or volume. Interestingly, while coupled respiration of NADH via complex I was significantly increased by RT, complex II activity only slightly increased. That is, RT increased both complex I and complex II activity as it increased total mitochondrial respiratory capacity, but appreciably shifted the relative contribution towards complex I. Moreover, the mRNA of COX4I1 (Complex IV) and NAMPT, which controls synthesis of $\mathrm{NAD}^{+}$, was elevated. Unfortunately, this study is limited in scope as its subjects were all young; nevertheless, it shows that RT indeed enhances oxidative coupling in skeletal muscle, and that it does so independently of mitochondrial biogenesis or any increase in mitochondrial volume, consistent with our previous speculation on RT.

Similar improvements have been demonstrated to be conferred by RT in aged individuals. In a study by Parise et al. [2], 28 older adults (age $68.5 \pm 5.1$ years) performed whole-body RT three times per week for 14 weeks ranging between 10 and 12 repetitions per set for 3 sets with 2 min of rest between each set [2]. Following this RT intervention, ETC complex IV activity increased along with mitochondrial creatine kinase content, while mitochondrial mass, mtDNA deletions, and other ETC complex activities remained unchanged [2], suggesting again a qualitative improvement in mitochondrial function independent of mitochondrial volume. More interestingly, $\mathrm{RT}$ reduced oxidative stress as measured by a $17.5 \%$ decrease in urinary 8-OHdG, without any change in antioxidant enzyme protein content [2]. Thus, it seems that RT may decrease oxidative stress not by inducing antioxidant activity, but rather by reducing ETC electron leakage by enhancing ETC electron flux, as observed in the increase in complex IV/I + III ratio [2]. However, any potential antioxidant benefits of RT must be taken with a grain of salt as a recent 2020 meta-analysis including 614 old (average age 68.1) individuals concluded that RT is not effective in reducing global markers of oxidative stress [90]. Nevertheless, it could be possible that RT, by reducing electron leakage, still reduces oxidative stress locally within skeletal muscle mitochondria without altering global markers of redox homeostasis.

Likewise, a recent 2020 study [91] reported significant increases in the abundance of oxidative phosphorylation complex proteins I-V without any significant change in mitochondrial biogenesis proteins, PGC- $1 \alpha$, TFAM, and
NRF1, following 10 weeks of full-body RT in untrained old (59 \pm 4 years) adults, further confirming the idea that RT acts to enhance qualitative mitochondrial capacity by improving coupling efficiency. Additionally, mitochondrial fusion proteins Mfn1, Mfn2, and Opa1 were found to be elevated. A previously mentioned trial by Jubrias et al. [73] featured not only the aforementioned ET group, but also an RT group. The untrained older individuals (average age 69.2 \pm 0.6 years) participated in a periodized RT program consisting of both lighter days (3 sets of 10-15 repetitions) and heavy days (3-5 sets of 4-8 repetitions) for a total of 3 sessions per week over a 24-week period. Remarkably, this group experienced an increase in skeletal muscle oxidative capacity even greater than that of the ET group. However, this 57\% increase in oxidative capacity was accompanied by a $31 \%$ in mitochondrial density in addition to $10 \%$ increase in skeletal muscle mass, as expected. While these results do show that RT can, in some cases, induce mitochondrial biogenesis, it is nevertheless consistent with the idea that RT increases the ratio of oxidative capacity to mitochondrial volume, therefore improving coupling efficiency.

In contrast, low volume and low repetition RT appear to be ineffective at inducing mitochondrial changes, despite improving muscular strength. For instance, a study by Flack et al. [92] reported unchanged oxidative capacity and ROS production following 12 weeks of full-body RT 3x/week in untrained older ( $\geq 60$-year-old) males. One factor in this study that sets it apart from the other RT studies, and is likely responsible for its disparate outcomes, is that subjects performed only one set of each exercise per session. Thus, low volume RT appears inept at inducing mitochondrial changes.

Like low volume RT, low repetition RT, or maximal voluntary contraction (MVC) RT seems not to carry the same mitochondrial benefits as moderate-to-high repetition, and volume training. Demonstrating this, a recent study found that when 10 older adults ( $75 \pm 9$ years) underwent an 8-week regiment of MVC knee-extension quadriceps training, maximal ADP-stimulated respiration rate actually decreased in conjunction with decreased complex I activity and peak oxidative ATP synthesis [93]. One caveat of this study is that, as opposed to other RT studies involving full-body training, this study only involved performing one isolation exercise- single leg knee extensions. Nevertheless, these findings must be considered in light of the functional skeletal muscle improvements conferred by resistance exercise, as illustrated in multiple interventional studies demonstrating its ability to ameliorate severe sarcopenia [94] and protect against progression in pre-sarcopenia [95]. Moreover, these results make sense in light of the fact that low repetition MVC training as executed in the study, is 
Table 1 Oxidative mitochondrial outcomes of RT, ET and CT interventions

\begin{tabular}{|c|c|c|c|c|c|}
\hline Authors & Cohort & Training type & $\begin{array}{l}\text { Intensity }[\mathrm{ET}] / \\
\text { repetition range }[\mathrm{RT}]\end{array}$ & $\begin{array}{l}\text { Intervention } \\
\text { duration/ } \\
\text { frequency }\end{array}$ & Primary outcomes \\
\hline Menshikova et al. [28] & $\begin{array}{l}\text { Sedentary older }(67 \pm 0.6 \\
\text { years) adults ( } 5 \text { men, } 3 \\
\text { women) }\end{array}$ & $\mathrm{ET}$ & $\begin{array}{l}\text { 30-40 min of HR } 50-70 \% \\
\text { of } \mathrm{VO}_{2} \text { max (progres- } \\
\text { sive) }\end{array}$ & $\begin{array}{l}12 \text { weeks } \\
4-6 x / \text { week }\end{array}$ & $\begin{array}{l}\text { } E T C \text { Activity } \\
\uparrow N A D H \text { Oxidase }(\mathrm{CI}) \\
\uparrow m \text { mAN/mitochondrial } \\
\text { biogenesis } \\
\uparrow \text { Complex I-IV activity }\end{array}$ \\
\hline Short et al. [14] & $\begin{array}{l}\text { Untrained men/women } \\
\text { (21-87 years) }\end{array}$ & ET & $\begin{array}{l}20 \text { min at } 70 \% \text { of max } H R \\
\text { (start) } \\
40 \text { min at } 80 \% \text { of max } H R\end{array}$ & $\begin{array}{l}16 \text { weeks } \\
3 x / \text { week (start) } \\
4 x / \text { week (end) }\end{array}$ & $\begin{array}{l}\uparrow \text { Complex IV activity } \\
\uparrow \text { Citrate synthase } \\
\uparrow \text { COX4, ND4 (mito. } \\
\text { Enzymes) } \\
\uparrow P G C-1 a, \text { TFAM, NRF-1 }\end{array}$ \\
\hline Broskey et al. [27] & $\begin{array}{l}\text { Sedentary men and } \\
\text { women (60- } 80 \text { years) }\end{array}$ & $\mathrm{ET}$ & $\begin{array}{l}75 \% \text { of max HR for } \\
30-60 \text { min (progres- } \\
\text { sive along course of } \\
\text { intervention) }\end{array}$ & $\begin{array}{l}16 \text { weeks } \\
3 x / \text { week }\end{array}$ & 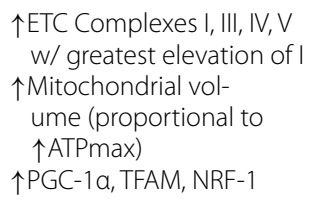 \\
\hline Conley et al. [72] & $\begin{array}{l}\text { Recreationally active } \\
\text { older ( } 69.5 \pm 1.2 \text { years) } \\
\text { men and women }\end{array}$ & ET & $\begin{array}{l}60 \%->80-85 \% \text { of max } \\
\text { HR for } 20 \text { min on two } \\
\text { different exercises }\end{array}$ & $\begin{array}{l}24 \text { weeks } \\
3 x / \text { week }\end{array}$ & $\begin{array}{l}\uparrow \text { ATPmax (+ } 31 \% \text { oxidative } \\
\text { capacity) } \\
\text { (Disproportionate to } \\
\text { change in Mito vol.) }\end{array}$ \\
\hline Jubrias et al. [73] & $\begin{array}{l}\text { Untrained older } \\
\text { (69.2 } \pm 0.6 \text { years) men } \\
\text { and women }\end{array}$ & $\begin{array}{l}\text { RT (Leg press + arm } \\
\text { training + shoulder } \\
\text { lifts) }\end{array}$ & $\begin{array}{l}3 \text { sets of } 10-15 \text { repeti- } \\
\text { tions (lighter days) } \\
3-5 \text { sets of } 4-8 \text { repeti- } \\
\text { tions (heavier days) }\end{array}$ & $\begin{array}{l}24 \text { weeks } \\
3 x / \text { week }\end{array}$ & $\begin{array}{l}\text { } 57 \% \text { skeletal muscle } \\
\text { oxidative capacity } \\
\text { (Greater than that of cor- } \\
\text { responding ET group) } \\
\text { 个31\% mitochondrial } \\
\text { density }\end{array}$ \\
\hline Mesquita et al. [91] & $\begin{array}{l}\text { Untrained aged } \\
\text { (59 } \pm 4 \text { years) men and } \\
\text { women }\end{array}$ & RT (Full Body) & $\begin{array}{l}3 \text { sets of } 10-12 \text { repeti- } \\
\text { tions with } 1 \text { min rest } \\
\text { between sets }\end{array}$ & $\begin{array}{l}10 \text { weeks } \\
2 x / \text { week }\end{array}$ & $\begin{array}{l}\text { } \text { OXPHOS Proteins: } \\
\uparrow 180 \% \text { CI, 39\% CII, 89\% } \\
\text { CIII, 43\% CIV, 78\% CV } \\
\text {-Unchanged PGC-1a and } \\
\text { TFAM }\end{array}$ \\
\hline Porter et al. [89] & Untrained young men & RT (Full-body) & $\begin{array}{l}\text { 3-4 sets of } 8-10 \text { repeti- } \\
\text { tions with } 1-2 \text { min rest } \\
\text { between sets }\end{array}$ & $\begin{array}{l}12 \text { weeks } \\
3 x / \text { week }\end{array}$ & $\begin{array}{l}\uparrow \uparrow \text { ETC Complex I activity } \\
\uparrow \text { Coupled (P) and uncou- } \\
\text { pled mitochondrial } \\
\text { respiration } \\
\uparrow C O X 411 / \text { NAMPT mRNA }\end{array}$ \\
\hline Flack et al. [92] & $\begin{array}{l}\text { Untrained older } \\
\qquad(\geq 60 \text { years) males }\end{array}$ & RT (Full-body) & 1 set of $8-12$ repetitions & $\begin{array}{l}12 \text { weeks } \\
3 x / \text { week }\end{array}$ & $\begin{array}{l}\text { No change in oxidative } \\
\text { capacity or ROS produc- } \\
\text { tion }\end{array}$ \\
\hline Parise et al. [2] & $\begin{array}{l}\text { Untrained older } \\
\text { men/women } \\
\text { (68.5 } \pm 5.1 \text { years) }\end{array}$ & RT (Full-body) & $\begin{array}{l}3 \text { sets of } 10-12 \text { repeti- } \\
\text { tions with } 2 \text { min rest } \\
\text { between sets }\end{array}$ & $\begin{array}{l}14 \text { weeks } \\
3 x / \text { week }\end{array}$ & $\begin{array}{l}\uparrow \text { ETC Complex IV activity } \\
\downarrow \text { Oxidative stress } \\
\downarrow 17.5 \% 8-\mathrm{OHdG}\end{array}$ \\
\hline Berg et al. [93] & $\begin{array}{l}\text { Older seden- } \\
\text { tary adults ( } 7 \text { men, } \\
3 \text { women, age } 75 \pm 9 \\
\text { years) }\end{array}$ & $\begin{array}{l}\text { RT (Single muscle group } \\
\text { MST) }\end{array}$ & $\begin{array}{l}4 \text { sets of } 4-5 \text { repeti- } \\
\text { tions with } 2 \text { min rest } \\
\text { between sets }\end{array}$ & $\begin{array}{l}8 \text { weeks } \\
3 x / \text { week }\end{array}$ & $\begin{array}{l}\downarrow \text { Complex I Activity } \\
\downarrow \text { Maximal ADP-dependent } \\
\text { respiration }\end{array}$ \\
\hline \multirow[t]{3}{*}{ Irving et al. [99] } & \multirow{3}{*}{$\begin{array}{l}\text { Older ( } \geq 61 \text { years) and } \\
\text { young (18-30 years) } \\
\text { sedentary men and } \\
\text { women }\end{array}$} & RT & 4 sets of $8-10$ repetitions & $\begin{array}{l}8 \text { weeks } \\
4 \text { days/week }\end{array}$ & $\begin{array}{l}\text {-No significant change in } \\
\text { oxidative capacity } \\
\text { 个PGC1a1.SIRT3, }\end{array}$ \\
\hline & & ET & $65 \% \mathrm{VO}_{2}$ max for $1 \mathrm{~h}$ & $\begin{array}{l}8 \text { weeks } \\
5 \text { days/week }\end{array}$ & 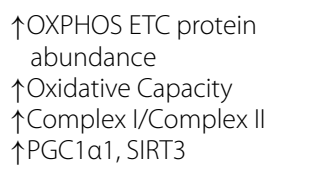 \\
\hline & & $\mathrm{CT}(\mathrm{ET}+\mathrm{RT})$ & $\begin{array}{l}65 \% \mathrm{VO}_{2} \text { max for } 30 \text { min, } \\
5 \text { days/week } \\
+ \\
2 / 3 \text { of RT group's resist- } \\
\text { ance volume, } \\
4 \text { days/week }\end{array}$ & 8 weeks & $\begin{array}{l}\uparrow \uparrow O X P H O S \text { ETC protein } \\
\text { abundance } \\
\uparrow \uparrow O x i d a t i v e \text { capacity } \\
\uparrow T F A M \text { (mitochondrial } \\
\text { biogenesis) }\end{array}$ \\
\hline
\end{tabular}


Table 1 (continued)

\begin{tabular}{|c|c|c|c|c|c|}
\hline Authors & Cohort & Training type & $\begin{array}{l}\text { Intensity }[\mathrm{ET}] / \\
\text { repetition range }[\mathrm{RT}]\end{array}$ & $\begin{array}{l}\text { Intervention } \\
\text { duration/ } \\
\text { frequency }\end{array}$ & Primary outcomes \\
\hline MacNeil et al. [100] & $\begin{array}{l}\text { Sedentary (for } 6 \text { months) } \\
\text { young adults }\end{array}$ & $\mathrm{CT}(\mathrm{RT}->\mathrm{ET}$ or $\mathrm{ET}->\mathrm{RT})$ & $\begin{array}{l}65 \% \mathrm{VO}_{2} \text { max for } \\
22.5 \text { min, immediately } \\
\text { followed by } 3 \text { sets of } \\
10 \text { repetitions with } \\
1 \text { min. rest, and vice } \\
\text { versa }\end{array}$ & $\begin{array}{l}6 \text { weeks } \\
3 x / \text { week }\end{array}$ & $\begin{array}{l}\uparrow \uparrow E T C \text { complex proteins } \\
I-V \\
\uparrow \uparrow M i t o c h o n d r i a l \text { biogen- } \\
\text { esis (PGC-1a, PRC) } \\
\text { Sequence of RT }>\text { ET is } \\
\text { superior than ET }>\text { RT at } \\
\text { upregulating complex II }\end{array}$ \\
\hline
\end{tabular}

entirely anaerobic, deriving most of its energy glycolytically as well as from phosphocreatine and therefore has little to do with mitochondrial processes or type I oxidative fibers.

Thus, as the repetition range increases (and the \%MVC decreases), the benefits of RT become increasingly oxidative and energetic in nature, overlapping to a greater degree with the improvements conferred by ET. So while low repetition MVC RT confers functional benefits that attenuate sarcopenic dysfunction, such improvements may come completely independent of mitochondrial changes. An additional advantage of high repetition RT is that it may be more accessible to older individuals who lack the endurance necessary to engage in ET forms such as running or cycling or may risk injury bearing heavy loads with higher \% MVC training. Moderate repetition $\mathrm{RT}$, on the other hand, improves oxidative capacity as does ET, and even appears to be more effective at improving mitochondrial coupling efficiency and inducing qualitative changes than ET. Given that ET, such as running, may be unfeasible for older individuals, we speculate whether high [15-20] repetition RT would garner similar mitochondrial improvements to ET or CT and be a safer and more accessible option for older individuals. While it has been demonstrated that high repetition, low load RT can be equally as effective as low repetition, high load RT in inducing muscle hypertrophy $[96,97]$, the effects of high repetition training on mitochondrial energetics remain unstudied, and thus warrant investigation.

\section{Concurrent training-the best of both worlds?}

Given the independent benefits of endurance and resistance training on mitochondrial aging and sarcopenia, the potential of combined endurance and resistance exercise is worthy of investigation. RT and ET each hold their own unique benefits in the context of sarcopenia and aging. RT serves to maintain and improve mobility, strength, and movement in a way that both protects against joint degeneration and preserves skeletal muscle function. ET improves mitochondrial energetics, thereby enhancing metabolic flexibility as well as increasing "muscle quality". These are highly synergistic improvements, working together to stave off both the molecular and macroscopic changes that are incurred with aging. Therefore, concurrent, or "combined", training is a putative intervention to preserve energetic and functional health of skeletal muscle with aging.

One study demonstrated that RT actually amplifies induction of mitochondrial biogenesis by ET when performed subsequent to ET, as seen in significantly higher increases in PGC-1 $\alpha$ and PRC [98]; In addition, RT and ET together, but not ET alone, effectively activated mTOR signaling [98]. Concurrent training (CT) may alter adaptations compared to single mode training, but the mechanisms of interaction and the implications of socalled "interference" caused by antagonistic signaling are poorly understood.

In a comprehensive clinical trial by Irving et al. [99], both old and young sedentary individuals underwent 8 weeks of either ET, RT, or CT. While all three training modalities predictably resulted in positive changes in muscle strength and cardiorespiratory fitness, only ET and $\mathrm{CT}$ engendered beneficial mitochondrial changes and improvements in oxidative phosphorylation capacity. Interestingly, CT produced even more robust energetic benefits than ET alone despite consisting of $50 \%$ of the aerobic volume of the solely ET protocol ( $30 \mathrm{~min}$ vs $1 \mathrm{~h}$ of cycling, respectively), suggesting that RT somehow amplifies the beneficial effects of ET when performed adjunctly. CT moreover appeared to be the most effective in improving overall muscle quality in the older subjects. Also of note is that the RT and CT groups performed 4 sets of 8-10 repetitions, a much higher, and therefore somewhat more aerobic, repetition range than that in the aforementioned low repetition, MVC RT study, which reported no improvements in oxidative capacity. While this study does not specify whether CT was performed in the order of RT followed by ET, or vice versa, other data has suggested that order of $\mathrm{CT}$ is mostly inconsequential to mitochondrial adaptations [100]. 

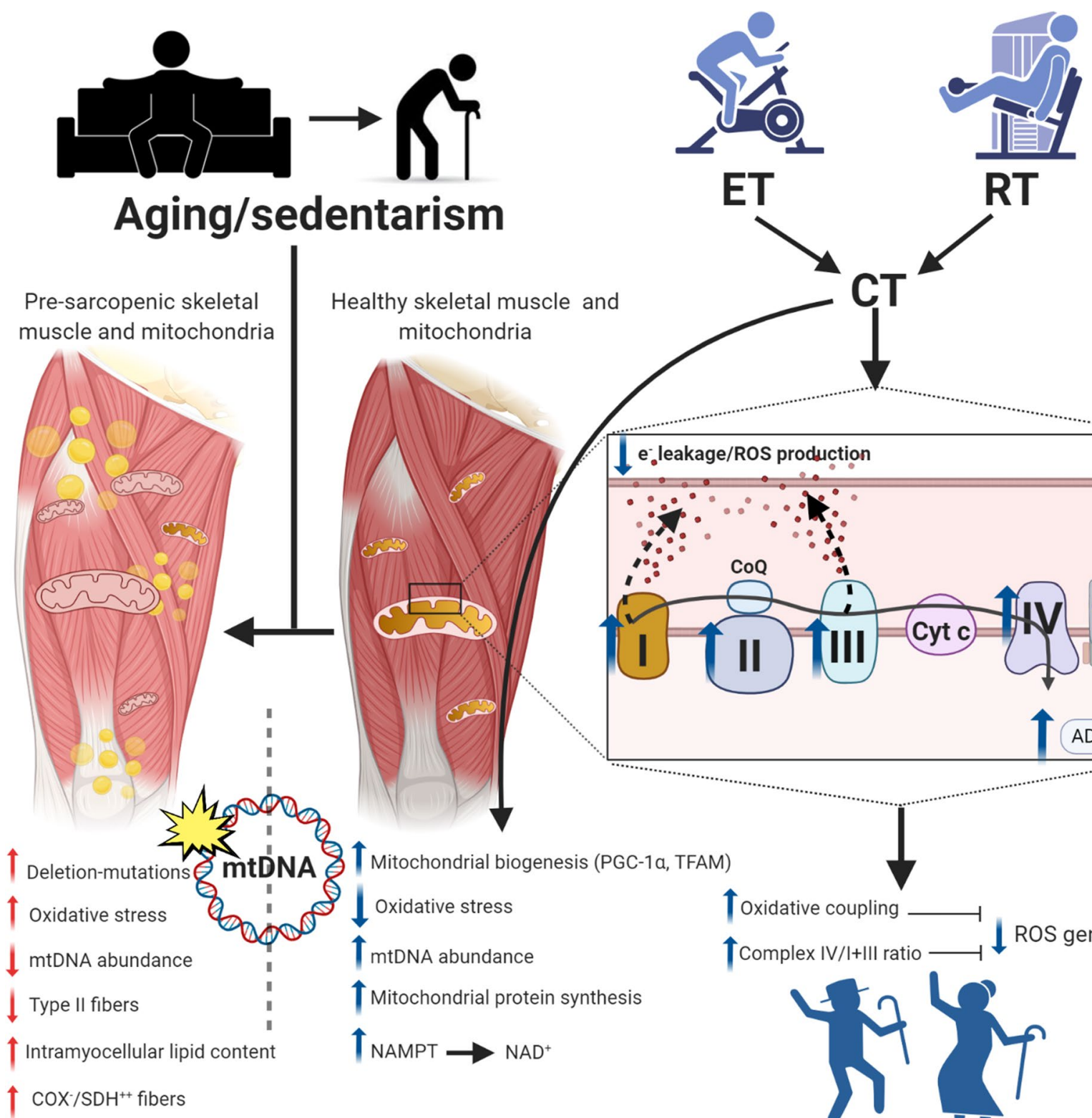

$\mathrm{RT}$
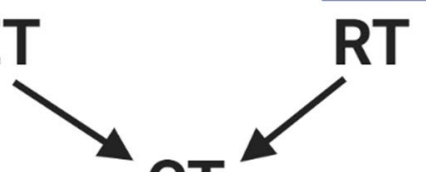
and PRC increased by $570 \%$ with little difference between the groups of differing protocol order [100]. Then, over the next 6 weeks participants performed SE or ES and were assayed for mitochondrial protein expression. CT increased protein content for all five ETC complexes as well as citrate synthase and COX. Importantly, ordering of training modality had negligible influence on molecular or performance effects, with one exception being that complex II saw increased gains in the SE group than the ES group [100]. While some studies indicate that CT order does not affect strength adaptions [101], other studies [102] as well as a recent meta-analysis [103] of such studies have concluded that SE is superior to ES in that performing RT first confers greater strength gains, without affecting aerobic adaptations. Moreover, a 2020 study found that while SE and ES training equally induce mitochondrial biogenesis, SE training additionally activates mTOR signaling [104]. Thus, it is a safe bet to sequence RT before ET in anti-aging exercise protocols (Table 1).

\section{Conclusions and future directions-how can we stave off sarcopenia and restore muscle mitochondrial health?}

Mitochondrial dysfunction in aged skeletal muscle is attributable to both the aging process, as well as to a reduction in physical activity. Although regular exercise may not abolish dysfunction completely, it can help to prolong specific functional aspects of the skeletal muscle and increase healthspan. This review has described the mechanisms involved in the deterioration of muscle function with age and has detailed how exercise training intercepts these processes.

We propose that moderate-to-high repetition RT followed by rotating high and moderate intensity ET is a putative strategy to reverse the molecular signatures of skeletal muscle aging, restore respiratory coupling efficiency and thereby reduce chronic ROS generation/mtDNA damage, and reverse the mitochondrial transcriptome toward that of a younger adult. On a phenotypic level, this effectively staves off sarcopenia, preserving muscle function and strength in addition to improving metabolic health (Fig. 1).

\footnotetext{
Abbreviations

ATP: Adenosine triphosphate; mtDNA: Mitochondrial DNA; NADH: Nicotinamide adenine dinucleotide; $\mathrm{FADH}_{2}$ : Flavin adenine dinucleotide; ETC: Electron transport chain; ADP: Adenosine diphosphate; ROS: Reactive oxygen species; P/O ratio: ATP produced per $\mathrm{O}_{2}$ consumed; $\mathrm{PCR}$ : Polymerase chain reaction; COX: Cytochrome-c oxidase; $\mathrm{COX}^{-} / \mathrm{SDH}^{++}$: Cytochrome-c oxidase negative/ succinate dehydrogenase-hyperreactive; MRS: Magnetic resonance spectroscopy; ET: Endurance training; UDG: Uracil DNA glycosylase; OGG1: Oxoguanine DNA glycosylase; RT: Resistance training; COX4I1: Complex IV; NAMPT: Nicotinamide phosphoribosyltransferase; MVC: Maximum voluntary contraction; CT: Concurrent training; SE: Strength-endurance; ES: Endurance-strength.
}

Acknowledgements Not applicable

\section{Authors' contributions}

$\mathrm{JG}$ and $\mathrm{CH}$ conceived the ideas for the manuscript. $\mathrm{CH}, \mathrm{JG}$, and VG drafted the manuscript. CH prepared the figure and table. $\mathrm{CH}, \mathrm{JG}$, and VG edited and revised the manuscript. All authors read and approved the final manuscript.

\section{Funding}

No funding agency was involved in the preparation of this manuscript.

Availability of data and materials

Not applicable.

Ethics approval and consent to participate

Not applicable.

Consent for publication

Not applicable.

\section{Competing interests}

The authors declare that they have no competing interests.

\section{Author details}

${ }^{1}$ Clinical Translation Unit (CTU), Tulane University, New Orleans, USA. ${ }^{2}$ Agency for Science, Technology \& Research (A*STAR), Singapore Bioimaging Consortium (SBIC), Singapore, Singapore. ${ }^{3}$ Healthy Longevity Translational Research Program, Yong Loo Lin School of Medicine, National University of Singapore (NUS), Singapore, Singapore. ${ }^{4}$ Department of Physiology, Yong Loo Lin School of Medicine, National University of Singapore, Singapore, Singapore. ${ }^{5}$ Centre for Healthy Longevity, National University Health System (NUHS), Singapore, Singapore.

Received: 21 December 2020 Accepted: 4 February 2021

Published online: 16 February 2021

\section{References}

1. Harman D. Aging: a theory based on free radical and radiation chemistry. J Gerontol. 1956;1 1 (3):298-300.

2. Parise G, Brose AN, Tarnopolsky MA. Resistance exercise training decreases oxidative damage to DNA and increases cytochrome oxidase activity in older adults. Exp Gerontol. 2005;40(3):173-80.

3. Parise G, Phillips SM, Kaczor JJ, Tarnopolsky MA. Antioxidant enzyme activity is up-regulated after unilateral resistance exercise training in older adults. Free Radic Biol Med. 2005;39(2):289-95.

4. Navarro A, Boveris $A$. The mitochondrial energy transduction system and the aging process. Am J Physiol Cell Physiol. 2007;292(2):C670-86.

5. Lesnefsky EJ, Hoppel CL. Oxidative phosphorylation and aging. Ageing Res Rev. 2006;5(4):402-33.

6. Cadenas S, Buckingham JA, St-Pierre J, Dickinson K, Jones RB, Brand MD. AMP decreases the efficiency of skeletal-muscle mitochondria. Biochem J. 2000;351(Pt 2):307-11.

7. Harper ME, Bevilacqua L, Hagopian K, Weindruch R, Ramsey JJ. Ageing, oxidative stress, and mitochondrial uncoupling. Acta Physiol Scand. 2004:182(4):321-31.

8. Mansouri A, Muller FL, Liu Y, Ng R, Faulkner J, Hamilton M, et al. Alterations in mitochondrial function, hydrogen peroxide release and oxidative damage in mouse hind-limb skeletal muscle during aging. Mech Ageing Dev. 2006;127(3):298-306.

9. Nakamura S, Takamura T, Matsuzawa-Nagata N, Takayama H, Misu H, Noda $\mathrm{H}$, et al. Palmitate induces insulin resistance in H4IIEC3 hepatocytes through reactive oxygen species produced by mitochondria. J Biol Chem. 2009;284(22):14809-18.

10. Kumaran S, Panneerselvam KS, Shila S, Sivarajan K, Panneerselvam C Age-associated deficit of mitochondrial oxidative phosphorylation in skeletal muscle: role of carnitine and lipoic acid. Mol Cell Biochem. 2005;280(1-2):83-9.

11. Barcena C, Mayoral P, Quiros PM. Mitohormesis, an antiaging paradigm. Int Rev Cell Mol Biol. 2018;340:35-77. 
12. Mason S, Wadley GD. Skeletal muscle reactive oxygen species: a target of good cop/bad cop for exercise and disease. Redox Rep. 2014;19(3):97-106.

13. Musci RV, Hamilton KL, Linden MA. Exercise-induced mitohormesis for the maintenance of skeletal muscle and healthspan extension. Sports. 2019;7(7):170.

14. Short KR, Vittone JL, Bigelow ML, Proctor DN, Rizza RA, CoenenSchimke JM, et al. Impact of aerobic exercise training on age-related changes in insulin sensitivity and muscle oxidative capacity. Diabetes. 2003;52(8):1888-96

15. Wanagat J, Cao Z, Pathare P, Aiken JM. Mitochondrial DNA deletion mutations colocalize with segmental electron transport system abnormalities, muscle fiber atrophy, fiber splitting, and oxidative damage in sarcopenia. FASEB J. 2001;15(2):322-32.

16. Bua E, Johnson J, Herbst A, Delong B, McKenzie D, Salamat S, et al. Mitochondrial DNA-deletion mutations accumulate intracellularly to detrimental levels in aged human skeletal muscle fibers. Am J Hum Genet. 2006;79(3):469-80.

17. Bua EA, McKiernan SH, Wanagat J, McKenzie D, Aiken JM. Mitochondrial abnormalities are more frequent in muscles undergoing sarcopenia. J Appl Physiol. 2002;92(6):2617-24.

18. Herbst A, Pak JW, McKenzie D, Bua E, Bassiouni M, Aiken JM. Accumulation of mitochondrial DNA deletion mutations in aged muscle fibers: evidence for a causal role in muscle fiber loss. J Gerontol A Biol Sci Med Sci. 2007:62(3):235-45.

19. Barazzoni R, Short KR, Nair KS. Effects of aging on mitochondrial DNA copy number and cytochrome c oxidase gene expression in rat skeletal muscle, liver, and heart. J Biol Chem. 2000;275(5):3343-7.

20. Rooyackers OE, Adey DB, Ades PA, Nair KS. Effect of age on in vivo rates of mitochondrial protein synthesis in human skeletal muscle. Proc Natl Acad Sci USA. 1996;93(26):15364-9.

21. Zhang YF. Age-dependent mitochondrial DNA 4977bp depletion in human skeletal muscle. Fa Yi Xue Za Zhi. 2007;23(6):438-40.

22. Herbst A, Wanagat J, Cheema N, Widjaja K, McKenzie D, Aiken JM. Latent mitochondrial DNA deletion mutations drive muscle fiber loss at old age. Aging Cell. 2016;15(6):1132-9.

23. Herbst A, Johnson CJ, Hynes K, McKenzie D, Aiken JM. Mitochondrial biogenesis drives a vicious cycle of metabolic insufficiency and mitochondrial DNA deletion mutation accumulation in aged rat skeletal muscle fibers. PLoS ONE. 2013;8(3):e59006.

24. Vincent AE, Rosa HS, Pabis K, Lawless C, Chen C, Grunewald A, et al. Subcellular origin of mitochondrial DNA deletions in human skeletal muscle. Ann Neurol. 2018;84(2):289-301.

25. Peterson CM, Johannsen DL, Ravussin E. Skeletal muscle mitochondria and aging: a review. J Aging Res. 2012;2012:194821.

26. Kwong LK, Sohal RS. Age-related changes in activities of mitochondrial electron transport complexes in various tissues of the mouse. Arch Biochem Biophys. 2000;373(1):16-22.

27. Broskey NT, Greggio C, Boss A, Boutant M, Dwyer A, Schlueter L, et al. Skeletal muscle mitochondria in the elderly: effects of physical fitness and exercise training. J Clin Endocrinol Metab. 2014;99(5):1852-61.

28. Menshikova EV, Ritov VB, Fairfull L, Ferrell RE, Kelley DE, Goodpaster $\mathrm{BH}$. Effects of exercise on mitochondrial content and function in aging human skeletal muscle. J Gerontol A Biol Sci Med Sci. 2006:61(6):534-40.

29. Short KR, Bigelow ML, Kahl J, Singh R, Coenen-Schimke J, Raghavakaimal S, et al. Decline in skeletal muscle mitochondrial function with aging in humans. Proc Natl Acad Sci USA. 2005;102(15):5618-23.

30. Russ DW, Kent-Braun JA. Is skeletal muscle oxidative capacity decreased in old age? Sports Med. 2004;34(4):221-9.

31. Rasmussen UF, Krustrup P, Kjaer M, Rasmussen HN. Experimental evidence against the mitochondrial theory of aging. A study of isolated human skeletal muscle mitochondria. Exp Gerontol. 2003:38(8):877-86.

32. Rasmussen UF, Krustrup P, Kjaer M, Rasmussen HN. Human skeletal muscle mitochondrial metabolism in youth and senescence: no signs of functional changes in ATP formation and mitochondrial oxidative capacity. Pflugers Arch. 2003;446(2):270-8.

33. Distefano G, Standley RA, Zhang X, Carnero EA, Yi F, Cornnell HH, et al. Physical activity unveils the relationship between mitochondrial energetics, muscle quality, and physical function in older adults. J Cachexia Sarcopenia Muscle. 2018;9(2):279-94.

34. Cannon DT, Bimson WE, Hampson SA, Bowen TS, Murgatroyd SR, Marwood S, et al. Skeletal muscle ATP turnover by 31P magnetic resonance spectroscopy during moderate and heavy bilateral knee extension. J Physiol. 2014;592(23):5287-300.

35. Cuthbertson DJ, Irwin A, Sprung VS, Jones H, Pugh CJ, Daousi C, et al. Ectopic lipid storage in non-alcoholic fatty liver disease is not mediated by impaired mitochondrial oxidative capacity in skeletal muscle. Clin Sci. 2014;127(12):655-63.

36. Kemp GJ, Ahmad RE, Nicolay K, Prompers JJ. Quantification of skeletal muscle mitochondrial function by 31P magnetic resonance spectroscopy techniques: a quantitative review. Acta Physiol. 2015:213(1):107-44.

37. Liu Y, Gu Y, Yu X. Assessing tissue metabolism by phosphorous-31 magnetic resonance spectroscopy and imaging: a methodology review. Quant Imaging Med Surg. 2017;7(6):707-26.

38. Phillips AC, Sleigh A, McAllister CJ, Brage S, Carpenter TA, Kemp GJ, et al. Defective mitochondrial function in vivo in skeletal muscle in adults with Down's syndrome: a 31P-MRS study. PLOS ONE. 2013;8(12):e84031.

39. Rzanny R, Stutzig N, Hiepe P, Gussew A, Thorhauer HA, Reichenbach $J R$. The reproducibility of different metabolic markers for muscle fiber type distributions investigated by functional (31)P-MRS during dynamic exercise. Z Med Phys. 2016;26(4):323-38.

40. Sleigh A, Savage DB, Williams GB, Porter D, Carpenter TA, Brindle KM, et al. 31P magnetization transfer measurements of Pi->ATP flux in exercising human muscle. J Appl Physiol. 2016;120(6):649-56.

41. Conley KE, Esselman PC, Jubrias SA, Cress ME, Inglin B, Mogadam $C$, et al. Ageing, muscle properties and maximal $O(2)$ uptake rate in humans. J Physiol. 2000;526(Pt 1):211-7.

42. Kent-Braun JA, Ng AV, Young K. Skeletal muscle contractile and noncontractile components in young and older women and men. J Appl Physiol. 2000;88(2):662-8.

43. Conley KE, Amara CE, Jubrias SA, Marcinek DJ. Mitochondrial function, fibre types and ageing: new insights from human muscle in vivo. Exp Physiol. 2007;92(2):333-9.

44. Anderson EJ, Neufer PD. Type II skeletal myofibers possess unique properties that potentiate mitochondrial $\mathrm{H}(2) \mathrm{O}(2)$ generation. Am J Physiol Cell Physiol. 2006;290(3):C844-51.

45. Demontis F, Piccirillo R, Goldberg AL, Perrimon N. Mechanisms of skeletal muscle aging: insights from Drosophila and mammalian models. Dis Model Mech. 2013;6(6):1339-52.

46. Deschenes MR. Effects of aging on muscle fibre type and size. Sports Med. 2004;34(12):809-24.

47. Anderson EJ, Neufer PD. Type II skeletal myofibers possess unique properties that potentiate mitochondrial $\mathrm{H} 2 \mathrm{O} 2$ generation. Am J Physiol Cell Ph. 2006;290(3):C844-51.

48. Koltai E, Hart N, Taylor AW, Goto S, Ngo JK, Davies KJ, et al. Ageassociated declines in mitochondrial biogenesis and protein quality control factors are minimized by exercise training. Am J Physiol Regul Integr Comp Physiol. 2012;303(2):R127-34.

49. Ljubicic V, Joseph AM, Adhihetty PJ, Huang JH, Saleem A, Uguccioni $\mathrm{G}$, et al. Molecular basis for an attenuated mitochondrial adaptive plasticity in aged skeletal muscle. Aging. 2009;1(9):818-30.

50. Fernandez-Marcos PJ, Auwerx J. Regulation of PGC-1alpha, a nodal regulator of mitochondrial biogenesis. Am J Clin Nutr. 2011;93(4):884S-S890

51. Virbasius JV, Scarpulla RC. Activation of the human mitochondrial transcription factor A gene by nuclear respiratory factors: a potential regulatory link between nuclear and mitochondrial gene expression in organelle biogenesis. Proc Natl Acad Sci USA. 1994;91(4):1309-13.

52. Kang C, Chung E, Diffee G, Ji LL. Exercise training attenuates agingassociated mitochondrial dysfunction in rat skeletal muscle: role of PGC-1alpha. Exp Gerontol. 2013;48(11):1343-50.

53. Konopka AR, Suer MK, Wolff CA, Harber MP. Markers of human skeletal muscle mitochondrial biogenesis and quality control: effects of age and aerobic exercise training. J Gerontol A Biol Sci Med Sci. 2014:69(4):371-8. 
54. Joseph AM, Adhihetty PJ, Buford TW, Wohlgemuth SE, Lees HA, Nguyen LM, et al. The impact of aging on mitochondrial function and biogenesis pathways in skeletal muscle of sedentary high- and low-functioning elderly individuals. Aging Cell. 2012;11(5):801-9.

55. Iqbal S, Ostojic O, Singh K, Joseph AM, Hood DA. Expression of mitochondrial fission and fusion regulatory proteins in skeletal muscle during chronic use and disuse. Muscle Nerve. 2013;48(6):963-70.

56. Sebastian D, Sorianello E, Segales J, Irazoki A, Ruiz-Bonilla V, Sala D, et al. Mfn2 deficiency links age-related sarcopenia and impaired autophagy to activation of an adaptive mitophagy pathway. EMBO J. 2016;35(15):1677-93.

57. Axelrod CL, Fealy CE, Mulya A, Kirwan JP. Exercise training remodels human skeletal muscle mitochondrial fission and fusion machinery towards a pro-elongation phenotype. Acta Physiol. 2019;225(4):e13216.

58. Tezze C, Romanello V, Desbats MA, Fadini GP, Albiero M, Favaro G, et al. Age-associated loss of OPA1 in muscle impacts muscle mass, metabolic homeostasis, systemic inflammation, and epithelial senescence. Cell Metab. 2017;25(6):1374-89.

59. Cavallini G, Donati A, Taddei M, Bergamini E. Evidence for selective mitochondrial autophagy and failure in aging. Autophagy. 2007;3(1):26-7.

60. Sakuma K, Kinoshita M, Ito Y, Aizawa M, Aoi W, Yamaguchi A. p62/ SQSTM1 but not LC3 is accumulated in sarcopenic muscle of mice. J Cachexia Sarcopenia Muscle. 2016;7(2):204-12.

61. Masiero E, Sandri M. Autophagy inhibition induces atrophy and myopathy in adult skeletal muscles. Autophagy. 2010;6(2):307-9.

62. Guan Y, Drake JC, Yan Z. Exercise-induced mitophagy in skeletal muscle and heart. Exerc Sport Sci Rev. 2019;47(3):151-6.

63. Sanchez AM, Candau R, Bernardi H. Recent data on cellular component turnover: focus on adaptations to physical exercise. Cells. 2019;8(6):542.

64. Vainshtein A, Tryon LD, Pauly M, Hood DA. Role of PGC-1alpha during acute exercise-induced autophagy and mitophagy in skeletal muscle. Am J Physiol Cell Physiol. 2015;308(9):C710-9.

65. Laker RC, Drake JC, Wilson RJ, Lira VA, Lewellen BM, Ryall KA, et al. Ampk phosphorylation of Ulk1 is required for targeting of mitochondria to lysosomes in exercise-induced mitophagy. Nat Commun. 2017;8(1):548.

66. Luo L, Lu AM, Wang Y, Hong A, Chen Y, Hu J, et al. Chronic resistance training activates autophagy and reduces apoptosis of muscle cells by modulating IGF-1 and its receptors, Akt/mTOR and Akt/FOXO3a signaling in aged rats. Exp Gerontol. 2013;48(4):427-36.

67. Conley KE, Jubrias SA, Amara CE, Marcinek DJ. Mitochondrial dysfunction: impact on exercise performance and cellular aging. Exerc Sport Sci Rev. 2007;35(2):43-9.

68. Turner DL, Hoppeler H, Claassen H, Vock P, Kayser B, Schena F, et al. Effects of endurance training on oxidative capacity and structural composition of human arm and leg muscles. Acta Physiol Scand. 1997; 161(4):459-64.

69. Freyssenet D, Berthon P, Denis C. Mitochondrial biogenesis in skeletal muscle in response to endurance exercises. Arch Physiol Biochem. 1996;104(2):129-41

70. Proctor DN, Sinning WE, Walro JM, Sieck GC, Lemon PW. Oxidative capacity of human muscle fiber types: effects of age and training status. J Appl Physiol. 1995;78(6):2033-8.

71. Balan E, Schwalm C, Naslain D, Nielens H, Francaux M, Deldicque L. Regular endurance exercise promotes fission, mitophagy, and oxidative phosphorylation in human skeletal muscle independently of age. Front Physiol. 2019;10:1088.

72. Conley KE, Jubrias SA, Cress ME, Esselman PC. Elevated energy coupling and aerobic capacity improves exercise performance in endurancetrained elderly subjects. Exp Physiol. 2013;98(4):899-907.

73. Jubrias SA, Esselman PC, Price LB, Cress ME, Conley KE. Large energetic adaptations of elderly muscle to resistance and endurance training. J Appl Physiol. 2001;90(5):1663-70.

74. Granata C, Oliveira RS, Little JP, Renner K, Bishop DJ. Training intensity modulates changes in PGC-1alpha and p53 protein content and mitochondrial respiration, but not markers of mitochondrial content in human skeletal muscle. FASEB J. 2016;30(2):959-70.

75. Egan B, Carson BP, Garcia-Roves PM, Chibalin AV, Sarsfield FM, Barron $\mathrm{N}$, et al. Exercise intensity-dependent regulation of peroxisome proliferator-activated receptor coactivator-1 mRNA abundance is associated with differential activation of upstream signalling kinases in human skeletal muscle. J Physiol. 2010;588(Pt 10):1779-90.

76. Russell AP, Feilchenfeldt J, Schreiber S, Praz M, Crettenand A, Gobelet $C$, et al. Endurance training in humans leads to fiber type-specific increases in levels of peroxisome proliferator-activated receptorgamma coactivator-1 and peroxisome proliferator-activated receptoralpha in skeletal muscle. Diabetes. 2003;52(12):2874-81.

77. Scribbans TD, Edgett BA, Vorobej K, Mitchell AS, Joanisse SD, Matusiak $J B$, et al. Fibre-specific responses to endurance and low volume high intensity interval training: striking similarities in acute and chronic adaptation. PLoS ONE. 2014;9(6):e98119.

78. Radak Z, Kumagai S, Nakamoto H, Goto S. 8-Oxoguanosine and uracil repair of nuclear and mitochondrial DNA in red and white skeletal muscle of exercise-trained old rats. J Appl Physiol. 2007;102(4):1696-701.

79. Radak Z, Naito H, Kaneko T, Tahara S, Nakamoto H, Takahashi R, et al. Exercise training decreases DNA damage and increases DNA repair and resistance against oxidative stress of proteins in aged rat skeletal muscle. Pflugers Arch. 2002;445(2):273-8.

80. Powers SK, Criswell D, Lawler J, Ji LL, Martin D, Herb RA, et al. Influence of exercise and fiber type on antioxidant enzyme activity in rat skeletal muscle. Am J Physiol. 1994;266(2 Pt 2):R375-80.

81. Kim YA, Kim YS, Oh SL, Kim HJ, Song W. Autophagic response to exercise training in skeletal muscle with age. J Physiol Biochem. 2013:69(4):697-705.

82. Lenhare L, Crisol BM, Silva VRR, Katashima CK, Cordeiro AV, Pereira $K D$, et al. Physical exercise increases Sestrin 2 protein levels and induces autophagy in the skeletal muscle of old mice. Exp Gerontol. 2017;97:17-21.

83. Tarawan VM, Gunadi JW, Setiawan, Lesmana R, Goenawan H, Meilina $D E$, et al. Alteration of autophagy gene expression by different intensity of exercise in gastrocnemius and soleus muscles of Wistar rats. J Sports Sci Med. 2019;18(1):146-54.

84. Goodpaster BH, Park SW, Harris TB, Kritchevsky SB, Nevitt M, Schwartz $A V$, et al. The loss of skeletal muscle strength, mass, and quality in older adults: the health, aging and body composition study. J Gerontol A Biol Sci Med Sci. 2006;61(10):1059-64.

85. Nilwik R, Snijders T, Leenders M, Groen BB, van Kranenburg J, Verdijk $L B$, et al. The decline in skeletal muscle mass with aging is mainly attributed to a reduction in type II muscle fiber size. Exp Gerontol. 2013:48(5):492-8

86. Westcott WL. Resistance training is medicine: effects of strength training on health. Curr Sports Med Rep. 2012;11(4):209-16.

87. Melov S, Tarnopolsky MA, Beckman K, Felkey K, Hubbard A. Resistance exercise reverses aging in human skeletal muscle. PLOS ONE. 2007;2(5):e465.

88. Moro T, Brightwell CR, Volpi E, Rasmussen BB, Fry CS. Resistance exercise training promotes fiber type-specific myonuclear adaptations in older adults. J Appl Physiol. 2020;128(4):795-804.

89. Porter C, Reidy PT, Bhattarai N, Sidossis LS, Rasmussen BB. Resistance exercise training alters mitochondrial function in human skeletal muscle. Med Sci Sports Exerc. 2015;47(9):1922-31.

90. Cuyul-Vasquez I, Berrios-Contreras L, Soto-Fuentes S, Hunter-Echeverria K, Marzuca-Nassr GN. Effects of resistance exercise training on redox homeostasis in older adults. A systematic review and meta-analysis. Exp Gerontol. 2020;138:111012.

91. Mesquita PHC, Lamb DA, Parry HA, Moore JH, Smith MA, Vann CG, et al. Acute and chronic effects of resistance training on skeletal muscle markers of mitochondrial remodeling in older adults. Physiol Rep. 2020;8(15):e14526.

92. Flack KD, Davy BM, DeBerardinis M, Boutagy NE, McMillan RP, Hulver $\mathrm{MW}$, et al. Resistance exercise training and in vitro skeletal muscle oxidative capacity in older adults. Physiol Rep. 2016;4(13):12849.

93. Berg OK, Kwon OS, Hureau TJ, Clifton HL, Thurston TS, Le Fur Y, et al. Skeletal muscle mitochondrial adaptations to maximal strength training in older adults. J Gerontol A Biol Sci Med Sci. 2020;75:2269.

94. Martin Del Campo Cervantes J, Habacuc Macias Cervantes M, Monroy Torres R. Effect of a resistance training program on Sarcopenia and functionality of the older adults living in a nursing home. J Nutr Health Aging. 2019;23(9):829-36.

95. Vikberg S, Sorlen N, Branden L, Johansson J, Nordstrom A, Hult A, et al. Effects of resistance training on functional strength and muscle mass in 
70-year-old individuals with pre-sarcopenia: a randomized controlled trial. J Am Med Dir Assoc. 2019;20(1):28-34.

96. Schoenfeld BJ, Peterson MD, Ogborn D, Contreras B, Sonmez GT. Effects of low- vs. high-load resistance training on muscle strength and hypertrophy in well-trained men. J Strength Cond Res. 2015;29(10):2954-63.

97. Lixandrao ME, Ugrinowitsch C, Berton R, Vechin FC, Conceicao MS, Damas F, et al. Magnitude of muscle strength and mass adaptations between high-load resistance training versus low-load resistance training associated with blood-flow restriction: a systematic review and meta-analysis. Sports Med. 2018;48(2):361-78.

98. Wang L, Mascher H, Psilander N, Blomstrand E, Sahlin K. Resistance exercise enhances the molecular signaling of mitochondrial biogenesis induced by endurance exercise in human skeletal muscle. J Appl Physiol. 2011;111(5):1335-44.

99. Irving BA, Lanza IR, Henderson GC, Rao RR, Spiegelman BM, Nair KS. Combined training enhances skeletal muscle mitochondrial oxidative capacity independent of age. J Clin Endocrinol Metab. 2015;100(4):1654-63.

100. MacNeil LG, Glover E, Bergstra TG, Safdar A, Tarnopolsky MA. The order of exercise during concurrent training for rehabilitation does not alter acute genetic expression, mitochondrial enzyme activity or improvements in muscle function. PLoS ONE. 2014;9(10):e109189.

101. Wilhelm EN, Rech A, Minozzo F, Botton CE, Radaelli R, Teixeira BC, et al. Concurrent strength and endurance training exercise sequence does not affect neuromuscular adaptations in older men. Exp Gerontol. 2014;60:207-14

102. Cadore EL, Izquierdo M, Pinto SS, Alberton CL, Pinto RS, Baroni BM, et al. Neuromuscular adaptations to concurrent training in the elderly: effects of intrasession exercise sequence. Age. 2013;35(3):891-903.

103. Murlasits Z, Kneffel Z, Thalib L. The physiological effects of concurrent strength and endurance training sequence: a systematic review and meta-analysis. J Sports Sci. 2018;36(11):1212-9.

104. Shirai T, Aoki Y, Takeda K, Takemasa T. The order of concurrent training affects mTOR signaling but not mitochondrial biogenesis in mouse skeletal muscle. Physiol Rep. 2020;8(7):e14411.

\section{Publisher's Note}

Springer Nature remains neutral with regard to jurisdictional claims in published maps and institutional affiliations.
Ready to submit your research? Choose BMC and benefit from:

- fast, convenient online submission

- thorough peer review by experienced researchers in your field

- rapid publication on acceptance

- support for research data, including large and complex data types

- gold Open Access which fosters wider collaboration and increased citations

- maximum visibility for your research: over $100 \mathrm{M}$ website views per year

At BMC, research is always in progress.

Learn more biomedcentral.com/submissions 